\title{
Wastewater a Source of Nutrients for Crops Growth and Development
}

\author{
Ivan Tymchuk1*, Oksana Shkvirko1, Halyna Sakalova², Myroslav Malovanyy, \\ Tetiana Dabizhuk², Oksana Shevchuk², Oleksandr Matviichuk², Tamara Vasylinych² \\ 1 Viacheslav Chornovil Institute of Sustainable Development, Lviv Polytechnic National University, S. Bandera \\ Str. 12, Lviv, 79013, Ukraine \\ 2 Natural Sciences and Geography Faculty, Vinnytsia Mykhailo Kotsiubynskyi State Pedagogical University, \\ Vinnytsia, Ukraine \\ * Corresponding author's e-mail: i.s.tymchuk@gmail.com
}

\begin{abstract}
The article deals with the main methods of nutrient removal from wastewater, as well as presents promising technologies and techniques. Struvite was characterized by a complex phosphorus fertilizer. The influence of struvite on the processes of germination of cultivated plants was investigated. The possibility of creating a growth substrate as an inexpensive and effective alternative to the disposal of the man-made wastes that contain an organic component was identified. The composition of the growth substrate was selected to ensure its functional properties. The growth substrate was tested by bioindication. Subsequently, the modification of the substrate by adding natural sorbents.
\end{abstract}

Keywords: wastewater, struvite, sewage sludge (SS), bioindication, substrate.

\section{INTRODUCTION}

Today, the problem of efficient use of natural resources has become extremely serious, so the application of environmental technologies enabling to obtain nutrients and energy carriers from industrial wastes (Kanda et al. 2019), biological objects (Malovany et al. 2016) and organic pollutants (Malovany et al. 2019a) is an important task.

In recent years, there has been a tendency to reduce the use of phosphate, potassium and nitrogen fertilizers, which is associated with a decrease in the natural resources needed to produce such fertilizers. The solution to this problem may be the use of organic wastes containing phosphorus $(\mathrm{P})$, nitrogen $(\mathrm{N})$ and potassium $(\mathrm{K})$. One of such wastes is sewage sludge. According to (Yuan et al. 2016, Gryshko \& Korinovskaya, 2016), sewage sludge contains $1-3 \%$ nitrogen $(\mathrm{N}), 1-5 \%$ phosphorus $(\mathrm{P})$ and $0.2-0.7 \%$ potassium $(\mathrm{K})$, on average, so it is an excellent source for the isolation or recovery of biogenic elements.
Literary sources discuss different ways of extracting the valuable components from sewage sludge, but most of them describe the ways to extract phosphorus, since its content in sewage sludge is highest. In (Munir et al. 2017, Mayer et al. 2016) the phosphorus recovery technologies that include precipitation in the form of struvite, nanofiltration, ion exchange and liquid-liquid extraction were described.

Currently, the technologies that are based on the precipitation of phosphorus minerals from sewage sludge have become widely used for phosphorus recovery, in the liquid fraction, their content is estimated from 1 to $5 \%$. Such phosphorus minerals can be precipitated in the form of struvite, hydroxyapatite or calcium phosphate. The advantage of such technology is the ability to obtain high quality phosphorus minerals that can find direct use in agriculture, and the deposited hydroxyapatite minerals contain very low concentrations of heavy metals 
and are therefore environmentally safe (Cieślik \& Konieczka, 2017, Shiba \& Ntuli, 2017, Tyagi $\&$ Lo, 2013a).

The phosphorus recovery by precipitation or crystallization is preferably carried out using the Phostrip or PRISA processes. In the Phostrip process, phosphorus is recovered from sewage sludge, which originates from an enhanced process of biological phosphorus removal and is precipitated as calcium phosphate or ammonium phosphate $\left(\mathrm{MgNH}_{4} \mathrm{PO}_{4} \cdot 6 \mathrm{H}_{2} \mathrm{O}\right.$ - struvite) (Sartorius et al., 2011).

The PRISA process involves crystallization of struvite from a solution of activated sludge (raw and digested). Such processes are partly combined with the methods of adsorption or ion exchange (Blöcher et al., 2012).

Much attention is paid to the separation of phosphorus from ash, which is formed by the incineration of sewage sludge. As a result of the thermal treatment of sewage sludge, ash contains much more phosphorus (from 5 to $11 \%$ ), which is associated with a decrease in the volume of burned materials (70-90\%). In the ash fraction, phosphorus is often found as $\mathrm{Fe}_{4}\left(\mathrm{P}_{4} \mathrm{O}_{12}\right)_{3}, \mathrm{Al}\left(\mathrm{PO}_{3}\right)_{3}$.

Most often, phosphorus is obtained from ash using mineral or organic acids such as $\mathrm{H}_{2} \mathrm{SO}_{4}$, $\mathrm{HNO}_{3}, \mathrm{HCl}, \mathrm{H}_{3} \mathrm{PO}_{4}$ citric or oxalic acid (Munir et al. 2017, Mayer et al. 2016, Havukainen et al., 2016).

The recovery of phosphorus from the ash requires prior hydrolysis, disintegration and dissolution, it uses processes such as Seaborne and PASCH. The Seaborne process hydrolyzes sewage sludge in an acidic environment using sulfuric acid. Heavy metals are precipitated in the form of sulfides and removed, while phosphorus is precipitated in the form of struvite (Blöcher et al., 2012, Kalogo \& Monteith, 2012).

The PASCH process is carried out by hydrolysis of sewage sludge with hydrochloric acid and solvent extraction to extract iron and heavy metals into the organic phase. Then, the phosphate is precipitated from the aqueous phase in the form of struvite or calcium phosphate (Blöcher et al., 2012).

The biological nutrient removal techniques, including anaerobic ammonia oxidation (ANAMMOX), reduced nitrification and denitrification; simultaneous nitrification and denitrification (SND) and non-oxygen denitrifying phosphorus removal are used to extract nitrogen from sewage sludge (Jin et al., 2014, De Vrieze et al., 2016).
There are also other processes for the recovery of sewage sludge elements, among which Crystalactor, AirPrex, Phosnix are worth mentioning (Blöcher et al., 2012, Zhou et al., 2017).

The organic and mineral compounds of nitrogen are present in wastewater of many industries: chemical, petrochemical, medical, microbiological, metallurgical, coke-chemical, food, agrochemical, as well as in underground and household waters. Purification of water from the nitrogen compounds by chlorination, ozonation, ultraviolet irradiation, ion exchange, electrolysis, demineralization requires expensive reagents and equipment; these methods are ineffective and difficult to operate. The wastewater of these industries is purified from the biogenic elements by the conventional biological methods (in aeration tanks), but the nitrogen compounds are practically not removed.

Development of new high-efficiency water treatment schemes at the existing wastewater treatment plants, as well as improving the existing wastewater treatment schemes is one way to solve the problem of the discharge of under-treated wastewater into water bodies. The use of nitridenitrification technology in combination with dephosphatization requires the improvement of the reagent purification of wastewater through a detailed study on the formation of crystalline hydrate, which is responsible for the properties and chemical composition of the biogenic mineral of struvite $-\mathrm{MgNH}_{4} \mathrm{PO}_{4} \cdot 6 \mathrm{H}_{2} \mathrm{O}$.

The main purpose of the study was to identify the possibility of creating a growth substrate as an inexpensive and effective alternative to the disposal of the man-made wastes that contain an organic component, as well as to study the influence of struvite on the processes of germination of cultivated plants.

\section{MATERIALS AND METHODS}

Mineral struvite has a glass shine with a Mohs hardness of 1.5 to 2 and has a low specific gravity of 1.7. It exhibits dielectric properties is a piezoelectric, sparingly soluble under neutral and alkaline conditions, but readily soluble in acid. The struvite can be used as a concentrated complex fertilizer of prolonged action (McGrown et al., 2001).

From solutions, magnesium-ammonium orthophosphate is crystallized as pyramidal and 
mica crystals and is formed according to the reaction:

$$
\begin{aligned}
& \mathrm{NH}^{4+}+\mathrm{Mg}^{2+}+\mathrm{PO}_{4}^{3-}+6 \mathrm{H}_{2} \mathrm{O}= \\
& \quad=\mathrm{MgNH}_{4} \mathrm{PO}_{4} \cdot 6 \mathrm{H}_{2} \mathrm{O} \downarrow
\end{aligned}
$$

therefore, this compound can be called synthetic (anthropogenic) struvite.

The complex of preliminary experimental studies on the deposition in the form of struvite of model solutions and model ion exchange concentrate (Sakalova et al., 2018, Malovanyy et al., 2019) obtained by ion exchange extraction of the ammonium ions from aqueous solutions of natural zeolite and cation exchanger KU with an initial concentration of $\mathrm{NH}_{4}^{+}-\mathrm{N} 40 \mathrm{mg} / \mathrm{dm}^{3}$ installed:

1. The reagent method allows the removal of ammonium and phosphate at the same time, reaching the fraction of adsorbed ions up to $95 \%$ and up to $98 \%$, respectively.

2. The most optimal conditions for the process of reagent deposition of ammonium nitrogen at an initial concentration of $\mathrm{NH}_{4}^{+}-\mathrm{N}-550 \mathrm{mg} / \mathrm{l}$ are $\mathrm{pH} 9$ and the stoichiometric ratio of $\mathrm{Mg}^{2+}$ : $\mathrm{NH}_{4}^{+}: \mathrm{PO}_{4}^{3-}=1,5: 1: 1,5$. The proportion of adsorbed $\mathrm{NH}_{4}^{+}-\mathrm{N}$ - ions is $52.69 \%$, and $\mathrm{PO}_{4}{ }^{3-}-96.6 \%$. At an initial concentration of $\mathrm{NH}_{4}^{+}-\mathrm{N}-470 \mathrm{mg} / \mathrm{l}$, the optimum conditions for the process of ammonium nitrogen reagent precipitation are $\mathrm{pH} 8.5$ and the stoichiometric ratio $\mathrm{Mg}^{2+}: \mathrm{NH}_{4}^{+}: \mathrm{PO}_{4}^{3-}=1.5: 1: 1.5$.

3. Moisture during drying of mineral fertilizer was established. The obtained results of sludge moisture made it possible to determine the formula of the crystal hydrate, which is close in number of water molecules to the formula of mineral fertilizer struvite $\mathrm{MgNH}_{4} \mathrm{PO}_{4} \cdot 6 \mathrm{H}_{2} \mathrm{O}$.

4. The behavior of the resulting precipitate obtained from the ion-concentrate concentrate, by thermal heating, makes it possible to state that the product can be used as a fertilizer on an industrial scale. During drying and granulation, the fertilizer will not lose nutrients (nitrogen and phosphorus).

\section{RESULTS AND DISCUSSION}

\section{Agrochemical evaluation of the fertilizer}

An agronomic evaluation of the fertilizer obtained by reagent precipitation of an ion exchange concentrate was conducted and its suitability for use in the organic crop production was established.
Since the phosphorus in the synthetic struvite is contained in the citric-soluble form; the use of citric acid solutions is proposed as one of the options for further studies. The solubility of magnesium-ammonium phosphate in water and in the aqueous citric acid solutions of small concentrations was pre-determined. The synthesized struvite was found to have a solubility coefficient in water $\mathrm{K}_{1}{ }^{20}=0.025$, in a $1 \%$ citric acid solution $\mathrm{K}_{2}^{20}=0,068$, in a $2 \%$ citric acid solution $\mathrm{K}_{3}^{20}=0,203$.

In order to determine the biological effectiveness of struvite, the laboratory studies were conducted to determine the germination of radish seeds (Raphanus sativus L.) of Sachs variety, and lettuce (Lactuca sativa L.) of the Grand variety. The effectiveness of synthetic struvite was determined by the following indicators: energy and germination of seeds, moisture of germinated seeds.

The seeds were germinated in Petri dishes at room temperature. The filter paper was used as the litter. Germination and energy of seed germination of sowing radish, lettuce sowing, and salad was determined in triplicate from a pure fraction of seeds of 30 pieces. The reliability of the averages of similarity was determined by the value of the smallest significant difference at the 5\% significance level $\mathrm{HIP}_{0,5}$.

The scheme of experimental studies:

- Control (distilled water);

- The first group

1.1. Application rate of magnesium - ammonium phosphate (MAP) $0.025 \mathrm{~g} / \mathrm{ml}$ of distilled water;

1.2. Application rate of MAP $0.068 \mathrm{~g} / \mathrm{ml}$ of distilled water;

- The second group

2.1. The rate of application of MAP $0.25 \mathrm{~g} / \mathrm{ml}$ of $1 \%$ citric acid solution;

2.2. The rate of application of MAP $0.068 \mathrm{~g} / \mathrm{ml}$ of $1 \%$ citric acid solution;

- The third group

3.1. Application rate of MAP $0.025 \mathrm{~g} / \mathrm{ml} 2 \%$ citric acid solution;

3.2. The rate of application of MAP $0.068 \mathrm{~g} / \mathrm{ml}$ of $2 \%$ citric acid solution.

The results of the studies on the germination of radish seeds (Raphanus sativus L.) of Sachs variety are presented in Table 1.

As a result of a five-day germination of the radish seeds it was found that in the control variant, in distilled water, the seeds germinated on the second day of the experiment. In the variants with 
Table 1. Influence of struvite on the germination of radish seeds (Raphanus sativus L.) of Sachs variety

\begin{tabular}{|c|c|c|c|c|c|}
\hline Experiment number & $\begin{array}{c}\text { Seed germination, } \\
\%\end{array}$ & $\begin{array}{c}\text { Deviation from } \\
\text { control, } \%\end{array}$ & \multirow{2}{*}{ HIP $_{0,5}$} & $\begin{array}{c}\text { Duration of } \\
\text { germination, days }\end{array}$ & $\begin{array}{c}\text { Germination } \\
\text { energy, } \%\end{array}$ \\
\hline 1. Control & 90.0 & - & & 1 & 90.0 \\
\hline 1.1. & 93.3 & 3.3 & \multirow{2}{*}{1.07} & 2 & 93.3 \\
\hline 1.2. & 93.3 & 3.3 & & 2 & 93.3 \\
\hline 2.1. & 90.0 & 0 & \multirow{2}{*}{0.86} & 2 & 90.0 \\
\hline 2.2. & 86.7 & -3.3 & & 3 & 86.7 \\
\hline 3.1. & 86.7 & -3.3 & \multirow{2}{*}{1.85} & 3 & 86.7 \\
\hline 3.2 & 80.0 & -10 & & 4 & 76.7 \\
\hline
\end{tabular}

citric acid solution, seed germination averaged $88,35 \%$ for the variants of the second group and $83,35 \%$ for the variants of the third group. In the variants with MAP solutions, higher germination rates were characteristic of aqueous solutions, but it is likely that the struvite retarded the germination of the test crop seeds. It can be stated unequivocally that the citric acid solution slows the germination of seeds of radish sowing and reduces the germination rates to a greater extent due to the acidification of the environment. The values of the moisture content of the radish seeds (Fig. 1) confirm that citric acid reduces the moisture content of germinated seeds, and this indicates a decrease in the effectiveness of its germination.

The results of germination of lettuce seeds (Lactuca sativa L.) of the Grand variety are presented in table 2. In all cases, germination of seeds occurred within 1-2 days, the values of germination of seeds and germination energy are the same.

The research results indicate that the use of struvite reduces germination and increases the germination time of lettuce sowing, salad. The citric acid solution, on the contrary, promotes the germination processes. Additional experiments on the germination of seeds using only citric acid solutions confirm the above: the seeds of lettuce sowed, lettuce sprouts in one day, and the germination of seeds, is $93.3 \%$ when using $1 \%$ citric acid solution and $97.7 \%$ at using $2 \%$ citric acid solution. Therefore, the use of struvite at the germination stage of lettuce.

According to the preferred variant of germination of radish seeds, a comparative agronomic evaluation of the mineral fertilizer struvite obtained by two variants was carried out:

- By reagent precipitation of the ion-exchange concentrate after purification of the model solution with natural zeolite, or cation exchanger KU with a concentration of amine ions of $40 \mathrm{mg} / \mathrm{l}$.

- By reagent precipitation of model solutions.

When using an aqueous solution with a dosage of struvite $0.025 \mathrm{~g} / \mathrm{ml}$, seed germination was 93.3\% for both variants (Fig. 2).

Therefore, these data suggest that the ability of synthetic struvite to effectively influence the processes of germination of radish seeds (Raphanus sativus L.) of Sachs variety and, apparently, the seeds of other plants of the Raphanus genus Brassicaceae family.

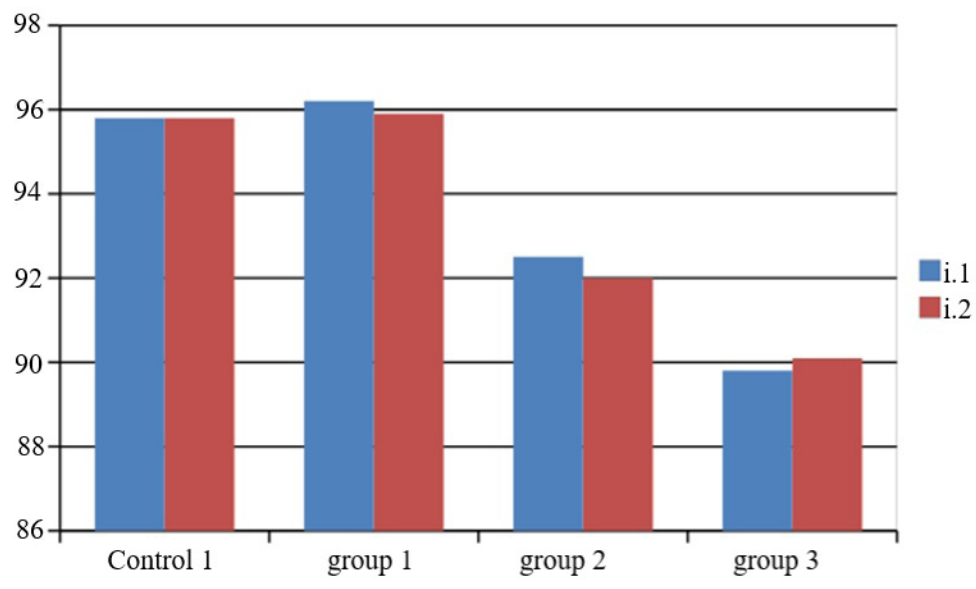

Fig. 1. Value of moisture level for germination (\%)of radish seeds, Sachs variety 
Table 2. Impact of struvite on seed germination of lettuce (Lactuca sativa L.) of the Grand variety

\begin{tabular}{|c|c|c|c|}
\hline $\begin{array}{c}\text { Experiment } \\
\text { number }\end{array}$ & $\begin{array}{c}\text { Seed } \\
\text { germination, } \\
\%\end{array}$ & $\begin{array}{c}\text { Deviation } \\
\text { from } \\
\text { control, \% }\end{array}$ & $\begin{array}{c}\text { Duration of } \\
\text { germination, } \\
\text { days }\end{array}$ \\
\hline 1. Control & 93.3 & - & 1 \\
\hline 1.1. & 83.3 & -10.0 & 2 \\
\hline 1.2. & 80.0 & -13.3 & 2 \\
\hline 2.1. & 83.3 & -10.0 & 2 \\
\hline 2.2 & 76.7 & -16.6 & 2 \\
\hline 3.2 & 97.7 & 4.4 & 1 \\
\hline 3.3 & 90.0 & -3.3 & 2 \\
\hline
\end{tabular}

The need for further studies to determine the effectiveness of struvite on the impact on the yield of different crops, as well as the ecotoxicological characteristics of the obtained fertilizer.

It was found that the method of obtaining struvite does not significantly affect the processes of seed germination and the value of germination moisture.

\section{The use of sewage sludge as a substrate for plant development}

Sludge, after the stage biological wastewater treatment, can be a potential source of nutrients that can provide growth and development of plants. However, the possibility of using them is limited by the presence in the sediments of heavy metals, as well as pathogenic microflora.

In world practice, the main method of sewage sludge disposal is landfilling. However, in such countries as Portugal, Ireland, the United Kingdom and Spain, $70 \%$ of all sewage sludge is used as fertilizers in agriculture. In Sweden and Finland, sewage sludge is used for land reclamation and land reclamation as a result of industrial development (Mininni et al., 2014, Di
Bonito, 2008). In the United States, research is being conducted on the possibility of using sewage sludge as biofuels, as well as converting it into biological oil that can be fractionated into various types of liquid fuels, including diesel and gasoline (Seiple et al., 2017). In Japan and the Netherlands, much effort has been made to recover the phosphorus sewage by applying the crystallization method. In addition, the latest phosphorus separation technologies have been developed based on the physicochemical and thermal treatment of sewage sludge to dissolve phosphorus and then recover it by burning (Matsumiya, 2014, Tyagi \& Lo, 2013b).

Many years of research show that sewage sludge can be used not only in agriculture as an organic mineral fertilizer, but also as an adjunct to building materials. Thus, according to (Johnson et al., 2014), a brick which consisted of a mixture of clay and shale with sewage sludge, was made. The use of ash heat-treated sewage sludge in combination with clay is an excellent material to produce lightweight aggregates. In addition, the use of sewage sludge in paving and cement production is promising. The development of the possibility of using sewage sludge to produce ceramic and glass products is also relevant. The results of studies show that in such products with a content of $5 \%$ of sewage sludge, their mechanical and water-absorbing properties increase (Martinez-Garcia et al., 2012).

Today, there are many methods for the disposal of sewage sludge: incineration, disposal, use in various industries, etc. The aerobic and anaerobic conversion methods are also used to dispose of sewage sludge. According to ( $\mathrm{Du} \& \mathrm{Li}, 2017$ ), humic acids are formed in the aerobic transformation of sewage sludge, while proteins and aromatic amino acids are the main components

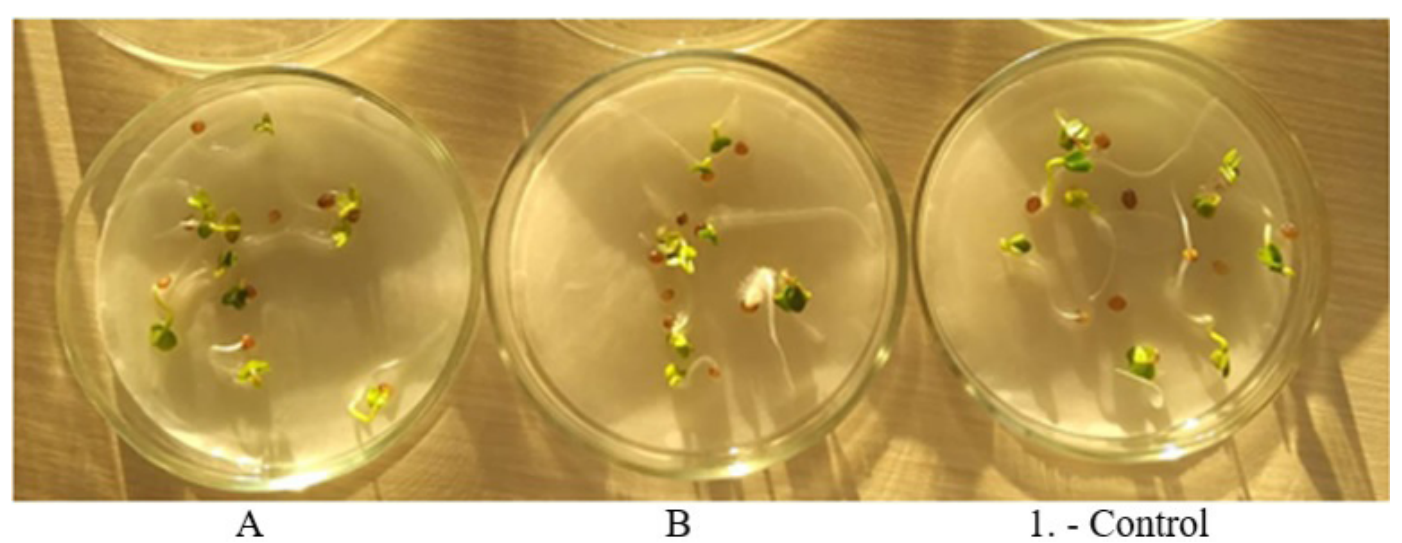

Fig. 2. Germination of radish seeds on the 5 th day after the beginning of the study. 
of anaerobic transformation, which indicates the possibility of using sewage sludge as organomineral fertilizers in agriculture. In many countries, most sewage sludge is used as a secondary raw material, for example, the production of organic fertilizers. The share of sewage sludge used in agriculture is the most significant compared to other methods of their disposal. This is due to the fact that the sewage sludge contains many nutrients, such as phosphorus, nitrogen, potassium and others, and is therefore a valuable organo-mineral fertilizer. One of the major limitations of using sewage sludge as fertilizers, is the presence of a number of pathogens and helminth eggs - dangerous to animals and humans - and many toxic substances, in particular, heavy metals, in their composition (Horodnii, 2013).

Therefore, the use of clean sludge in cultivated plants can pose a number of dangers, so it was decided to create a growth substrate, which would be based on the man-made wastes of organic origin, which could provide plants with nutrients, and the area of its use may be disturbed land on which to spend stage of biological reclamation.

The authors conducted the research on sewage sludge after the stage of biological treatment of water at Lviv MWTP (wastewater treatment plants), which are currently stored on sludge sites and occupy 22 ha.

In order to carry out the research, three main tasks were set:

- check the quality of sewage sludge, determine their composition and possibilities of use in the substrate;

- to create a primitive substrate from a mixture of sewage sludge and ordinary soil as well as check the possibility of plant growth and development on the substrate using bioindication;

- improve the created substrate to ensure its basic functions and to contain as much recycled material as possible.

Determination of qualitative indicators of sewage sludge was carried out on fresh samples (selected after the stage of purification, which were not stored on sludge sites), according to conventional methods on certified equipment in the laboratory of agrochemical, toxicological and radiological studies of ecological safety of soils and quality of the Lviv branch of the State institution "Soil protection institute of Ukraine". The following parameters were determined: humidity, $\mathrm{pH}$, organic matter content, basic biogenic elements (phosphorus, potassium, nitrogen), as well as trace elements and heavy metals. The detailed results of the analysis are presented in (Shkvirko et al., 2018), it was reported that sludge contains a significant amount of basic biogenic elements $(\mathrm{N}-3.56$; $\mathrm{P}-1.6$; $\mathrm{K}-0.3 \%)$, macroand microelements, as well as the available content of the organic component $(23,8 \%)$, which can provide nutrients to most plants; the content of available heavy metals forms in the test samples did not exceed the MPC; neutral acidity of the medium should not have an inhibitory effect on plant growth and development.

On the basis of the results of our research, it can be concluded that the chemical composition of the sewage sludge is relatively safe for use as a substrate. Thus, the first task was accomplished, so we proceeded to fulfill the next one.

The authors tried to create an elementary substrate of two components of fresh sludge and dark gray podzolic soil. For this purpose, these components were placed in Petri dishes in ratios (\%): 100: 0; 80:20; 60:40; 40:60; 20:80; 0: 100 . The optimal ratio was determined using bioindication. It was carried out in accordance with State Standards of DSTU ISO 11269-1: 2004 and 11269-2: 2002. Growth substrate comparisons were performed according to the control soil. Two species of plants belonging to one of the categories were selected for the experiment. Category 1 - monocotyledonous plants: rye, rice, oats, wheat, barley, common sorghum, corn. Category 2 - dicotyledonous: mustard white, rapeseed, radish and wild turnip, Chinese cabbage, garden watercress, tomato, beans. In our case, it is barley (Hordeum vulgare) and watercress (Lepidium sativum). Before use, the seeds of each crop were analyzed, and germination energy was determined. Bioindication was carried out in Petri dishes planting 10 seeds of etched (Vitavaks 200 FF) barley (similarity 95-97\%), untreated barley (similarity 95-97\%) and watercress (similarity 92-95\%). The experiments were carried out in four replicates to ensure the reliability of the studies.

The results of the studies show (Fig. 3) that the conditionally acceptable amount of sewage sludge for the production of substrate under such conditions may be $\approx 20 \%$, because on all bioindicating crops, the number of seedlings at the end of the experiment was not very different from control (etched barley $-17.5 \%$, watercress $-15 \%$ ), and in untreated barley exceeded it (by 2.5\%). 


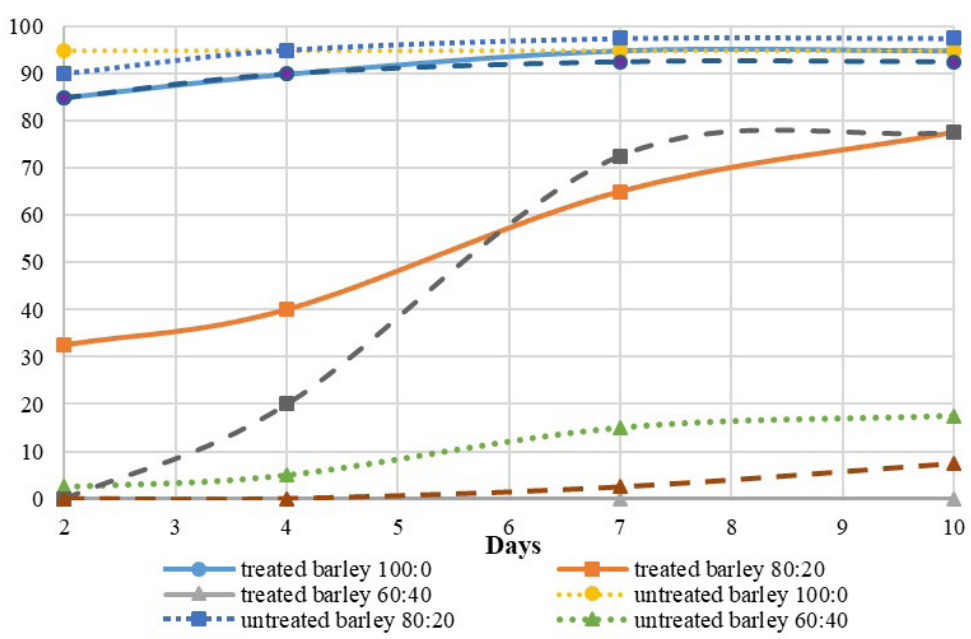

Fig. 3. Average germination of bioindicator plants in different substrates depending on time, $\%$

However, it should be noted that in the initial stages of the study (especially on watercress and etched barley), the substrates observed a delay in the appearance of the plants during the first 7 days of the study.

Adding $40 \%$ of sewage sludge to the substrate adversely affected all the variants studied, no sprouting was observed at all in the etched barley, in the untreated barley and watercress it amounted to $17.5 \%$ and $7.5 \%$ respectively. Therefore, it is not recommended to use this amount of sewage sludge with this substrate composition.

Therefore, having completed the second task, it was found that the use of $20 \%$ fresh sludge to create a substrate does not have a negative impact, and in some cases has a positive effect on the germination, growth and development of bioindicating plants. However, in the authors' opinion, this is not enough to try using such technology on an industrial scale, so the authors tried to complete the following task and improve the composition of the substrate, by introducing one component natural sorbent.

Natural sorbents are used to reduce the negative impact of heavy metals on the plant organism; they have a large buffer capacity and the ability to absorb contaminants, thus reducing their flow to the plant. Additionally, natural sorbents are a source of nutrients as well as substances that improve the physical condition of the soil. The fractional composition and density of the zeolites do not change significantly over time, which makes it possible to use them for a long time.

The studies were performed with fresh sediment, which was added to the dark gray podzolic soil in quantities $(\%): 0 ; 20 ; 25 ; 30 ; 35 ; 40$. The sorbent was added to the substrate in the amount $(\%): 0 ; 5 ; 7.5 ; 10$. The experiments were performed in triplicate to ensure the reliability of the studies. Bioindication was carried out in Petri dishes by planting seeds of barley (similarity $95-97 \%$ ).

The generalized results of plant germination are presented in Figure 4, the main parameters were recorded on the $10^{\text {th }}$ day of the experiment.

Additionally, the following indicators were observed during the experiment: time of emergence of sprouts, their number per day, total germination. At the end of the research: measuring the

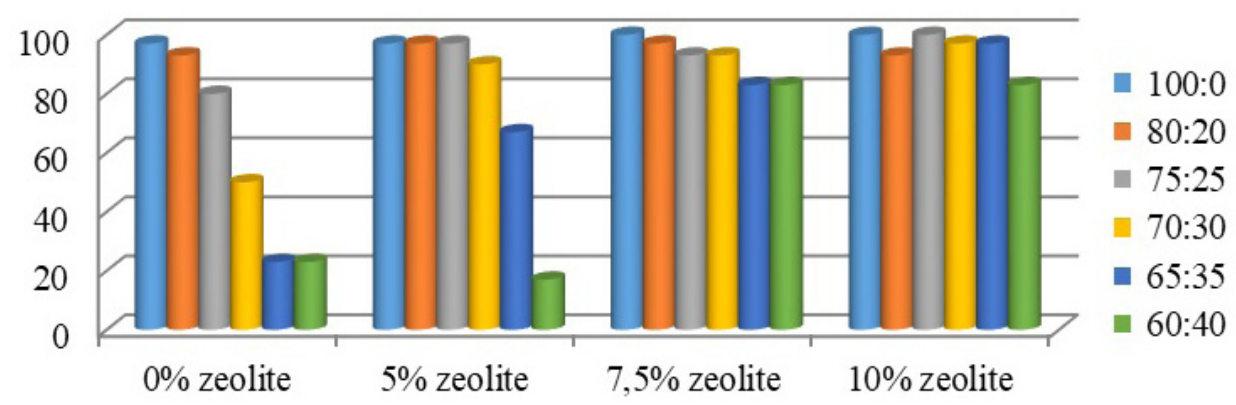

Fig. 4. Germination of barley on samples 
length and mass of the aerial part, measuring the length and mass of roots.

The results of studies to perform the third task reflect that in the variants where $40 \%$ of the precipitates were added without sorbent, the average germination was $23 \%$, and in the variants where $40 \%$ of the precipitates and $7.5 \%$ of the sorbents were germinated $-83.33 \%$. Moreover, in almost all variants where a mixture of sewage sludge and sorbents was used, a better development of the terrestrial part of the plant was observed with an increase in the proportion of sewage sludge in the substrate. Therefore, the results of studies show that sorbents need to be introduced into the composition of the substrate, which allows increasing the precipitate content up to $40 \%$, and possibly even more, without harming the plants.

After statistically processing the data obtained in this study using a correlation analysis, the following results were obtained:

- it was found that the \% zeolite content in the substrate directly correlates with root length $(0.45)$ and plant similarity $(0.52)$;

- the percentage of sewage sludge directly correlates with the height of the terrestrial part of the plant (0.49) and inversely correlates with root length (-0.54) and plant similarity $(-0.55)$;

- root length directly correlates with the index of plant similarity (0.81).

Thus, mainly the amount of sewage sludge added influences the growth and development of the terrestrial part of the plant, but the addition of a mixture of sorbents in the substrate enables to significantly increase the $\%$ of plants that will be able to sprout, and also has a positive effect on the development of the root system.

\section{CONCLUSIONS}

The conducted studies showed that the method of obtaining struvite does not significantly affect the processes of seed germination and the value of germination moisture. However, it effectively affects the germination processes of radish seeds (Raphanus sativus L.) of Sachs variety and, apparently, the seeds of other plants of the Raphanus genus of the Brassicaceae family. In the future, it is advisable to determine the effectiveness of struvite on the yield of different crops, as well as ecotoxicological characteristics.
The studies with sewage sludge showed that they can be used as a component to create a growth substrate, but there are limitations, because at an extremely high percentage, no germination of bioindicators occurred, the optimal proposed ratio of $\approx 20 \%$, but the addition of natural sorbents to the composition $(\approx 5-7.5 \%)$ enables to significantly increase the share of the man-made wastes used. Usually, the growth substrate needs to be improved relative to the component composition, so that as much as possible is made up of the manmade waste, and the least of ordinary fertile soil. However, even such a composition will be able to reduce the amount of fertile soil for biological reclamation almost in half, as well as decrease the cost of this process.

\section{REFERENCES}

1. Blöcher, C., Niewersch, C., \& Melin, T. 2012. Phosphorus recovery from sewage sludge with a hybrid process of low-pressure wet oxidation and nanofiltration. Water Research, 46(6), 2009-2019.

2. Cieślik, B., \& Konieczka, P. 2017. A review of phosphorus recovery methods at various steps of wastewater treatment and sewage sludge management. The concept of "no solid waste generation" and analytical methods. Journal of Cleaner Production, 142, 1728-1740.

3. Di Bonito, M. 2008. Sewage sludge in Europe and in the UK: Environmental impact and improved standards for recycling and recovery to land. Environmental Geochemistry, 251-286.

4. De Vrieze, J., Smet, D., Klok, J., Colsen, J., Angenent, L. T., \& Vlaeminck, S. E. 2016. Thermophilic sludge digestion improves energy balance and nutrient recovery potential in full-scale municipal wastewater treatment plants. Bioresource Technology, 218, 1237-1245.

5. Du, H., \& Li, F. 2017. Characteristics of dissolved organic matter formed in aerobic and anaerobic digestion of excess activated sludge. Chemosphere, 168, 1022-1031.

6. Gryshko, V.M., \& Korinovskaya, O.N. 2015. Influnce of organo-mineral fertilizers on the basis of precipitation of sewage on micromycetes cenosis. Gruntoznavstvo, 16 (1-2), 75-81.

7. Havukainen, J., Nguyen, M. T., Hermann, L., Horttanainen, M., Mikkilä, M., Deviatkin, I., \& Linnanen, L. 2016. Potential of phosphorus recovery from sewage sludge and manure ash by thermochemical treatment. Waste Management, 49, 221-229.

8. Horodnii, M.M. 2013. Problems of using sewage sludge for fertilizer production. Visnyk ahrarnoi nauky, 9, 45-50. (in Ukrainian). 
9. Jin, L., Zhang, G., \& Tian, H. 2014. Current state of sewage treatment in China. Water Research, 66, 85-98.

10. Johnson, O. A., Napiah, M., \& Kamaruddin, I. 2014. Potential uses of Waste Sludge in Construction Industry: A Review. Research Journal of Applied Sciences, Engineering and Technology, 8(4), 565-570.

11. Kanda, M., Malovanyy, M., Tymchuk, I., Odnorih, Z. 2019. Evaluation of the degree of environmental hazard from environmental pollution in the area of poultry farms impact. Environmental Problems, 4(3), 161-166.

12. Kalogo, Y., \& Monteith, H. (2012). Energy and Resource Recovery from Sludge. Water Intelligence Online, 11.

13. Malovanyy, M., Nikiforov, V., Kharlamova, O., Synelnikov O. 2016. Production of renewable energy resources via complex treatment of cyanobacteria biomass. Chemistry \& Chemical Technology, 10(2), 251-254.

14. Myroslav Malovanyy et al. 2019a. Perspective Technologies of the Treatment of the Wastewaters with High Content of Organic Pollutants and Ammoniacal Nitrogen. Journal of Ecological Engineering, 20(2), 8-15.

15. Malovanyy, M., Sakalova, H., Vasylinych, T., Kryklyvyi, R. 2019b. The Research on the Ammonium Concentrations in City Stocks and Further Sedimentation of Ion-Exchange Concentrate. Journal of Ecological Engineering, 20(1), 158-164.

16. Martinez-Garcia, C., Eliche-Quesada, D., PerezVillarejo, L., Iglesias-Godino F. J., \& Corpas-Iglesias, F. A. 2012. Sludge valorization from wastewater treatment plant to its application on the ceramic industry. Journal of Environmental Management, 95, 343-348.

17. Matsumiya, Y. 2014. Green Energy Production from Municipal Sewage Sludge in Japan, Japan Sewage Works Association.

18. Mayer, B. K., Baker, L. A., Boyer, T. H., Drechsel, P., Gifford, M., Hanjra, M. A., Rittmann, B. E. 2016. Total Value of Phosphorus Recovery. Environmental Science \& Technology, 50(13), 6606-6620.

19. McGrown, S.L., Basta, N.T., \& Brown, G.O. 2001. Use of diammonium phosphate to reduce heavy metal solubility and transport in smelter-contaminated soil: Journal of Environmental Quality, 30(2), 493-500.
20. Mininni, G., Blanch, A. R., Lucena, F., \& Berselli, S. 2014. EU policy on sewage sludge utilization and perspectives on new approaches of sludge management. Environmental Science and Pollution Research, 22 (10), 7361-7374.

21. Munir, M. T., Li, B., Boiarkina, I., Baroutian, S., Yu, W., \& Young, B. R. 2017. Phosphate recovery from hydrothermally treated sewage sludge using struvite precipitation. Bioresource Technology, 239, 171-179.

22. Sakalova, G., Vasylinych, T., Shevchuk, O., Tkachuk O. 2018. Perspectives of integration the technology of ion-exchanging ammonium extraction from the system of municipal drain water purification. Ukrainian Journal of Ecology, 8(1), 568-571.

23. Sartorius, C., von Horn, J., \& Tettenborn, F. 2011. Phosphorus Recovery from Wastewater-Stateof-the-Art and Future Potential. Proceedings of the Water Environment Federation, 2011(1), 299-316.

24. Seiple, T. E., Coleman, A. M., \& Skaggs, R. L. 2017. Municipal wastewater sludge as a sustainable bioresource in the United States. Journal of Environmental Management, 197, 673.

25. Shiba, N. C., \& Ntuli, F. 2017. Extraction and precipitation of phosphorus from sewage sludge. Waste Management, 60, 191-200.

26. Shkvirko, O., Tymchuk, I., \& Malovanyy, M. 2018. The use of bioindication to determine the possibility of sludge recovery after biological treatment of wastewater. Environmental Problems, 3(4), 258-264.

27. Tyagi, V. K., \& Lo, S.-L. 2013a. Microwave irradiation: A sustainable way for sludge treatment and resource recovery. Renewable and Sustainable Energy Reviews, 18, 288-305.

28. Tyagi, V. K. \& Lo, S.-L. 2013b. Sludge: A waste or renewable source for energy and resources recovery? Renewable and Sustainable Energy Reviews, 25, 708-728.

29. Yuan, H., Lu, T., Wang, Y., Chen, Y., \& Lei, T. 2016. Sewage sludge biochar: Nutrient composition and its effect on the leaching of soil nutrients. Geoderma, 267, 17-23.

30. Zhou, K., Barjenbruch, M., Kabbe, C., Inial, G., \& Remy, C. 2017. Phosphorus recovery from municipal and fertilizer wastewater: China's potential and perspective. Journal of Environmental Sciences, 52, 151-159. 